Check for updates

Cite this: J. Mater. Chem. A, 2018, 6, 13925

Received 4th May 2018

Accepted 24th June 2018

DOI: $10.1039 / c 8 t a 04138 e$

rsc.li/materials-a

\title{
Synthesis of mesoporous $\mathrm{LiMn}_{2} \mathrm{O}_{4}$ and $\mathrm{LiMn}_{2-x} \mathrm{Co}_{x} \mathrm{O}_{4}$ thin films using the MASA approach as efficient water oxidation electrocatalysts $\uparrow$
}

\author{
Fadime Mert Balci, ${ }^{a}$ Irmak Karakaya, ${ }^{a}$ Elif Pınar Alsaç, ${ }^{a}$ Muammer Yusuf Yaman, \\ Gülbahar Saat, ${ }^{a}$ Ferdi Karadas, (D) *ab Burak Ülgüt (D) ${ }^{\text {ab }}$ and Ömer Dag (iD *ab
}

\begin{abstract}
Mesoporous, highly active, robust, and cost-effective thin films are in big demand for water splitting by electrocatalysis. Molten-salt assisted self-assembly (MASA) is an effective method to synthesize mesoporous thin films. Transparent clear solutions of salts $\left(\mathrm{LiNO}_{3}\right.$ and $\left.\left[\mathrm{Mn}\left(\mathrm{H}_{2} \mathrm{O}\right)_{6}\right]\left(\mathrm{NO}_{3}\right)_{2}\right)$, acid $\left(\mathrm{HNO}_{3}\right)$, and surfactants (CTAB and P123) can be spin-coated over substrates as liquid crystalline (LC) films and calcined to obtain mesoporous high quality transparent thin films. A mixture of three salts ( $\mathrm{LiNO}_{3}$, $\left[\mathrm{Mn}\left(\mathrm{H}_{2} \mathrm{O}\right)_{6}\right]\left(\mathrm{NO}_{3}\right)_{2}$, and $\left.\left[\mathrm{Co}\left(\mathrm{H}_{2} \mathrm{O}\right)_{6}\right]\left(\mathrm{NO}_{3}\right)_{2}\right)$ also forms LC mesophases that can be calcined to produce mesoporous nanocrystalline mixed metal lithiates (meso- $\mathrm{LiMn}_{2-x} \mathrm{Co}_{x} \mathrm{O}_{4}$ ) with surface areas as large as $144 \mathrm{~m}^{2} \mathrm{~g}^{-1}$ (for $\mathrm{LiMn}_{1.5} \mathrm{Co}_{0.5} \mathrm{O}_{4}$ ). The synergic effects of these salts improve the pore-size of the final products; the pore size drops from around $11 \mathrm{~nm}$ (in the meso- $\mathrm{LiMn}_{2} \mathrm{O}_{4}$ ) to 6-7 nm in the meso$\mathrm{LiMn}_{1-x} \mathrm{CO}_{x} \mathrm{O}_{4}$. The meso- $\mathrm{LiMn}_{2-x} \mathrm{CO}_{x} \mathrm{O}_{4}$ films were tested at $\mathrm{pH} 13.6$ as water oxidation electrocatalysts over a broad range of $x$. While meso- $\mathrm{LiMn}_{2} \mathrm{O}_{4}$ shows a low activity towards water oxidation, the catalytic activity increases with the increasing $\mathrm{Co}(\mathrm{III})$ content of the films. The highest mass activity per cobalt, $1744 \mathrm{~A} \mathrm{~g} \mathrm{~g}^{-1}$, is obtained for meso- $\mathrm{LiMnCoO}_{4}$, which remains as a robust and efficient film even at a current density of $120 \mathrm{~mA} \mathrm{~cm}{ }^{-2}$.
\end{abstract}

\section{Introduction}

Preparation of mesoporous materials is highly important for the advancement of material-demanding technologies, such as catalysis, adsorption, and clean energy generation and storage. ${ }^{1-8}$ High surface area, large pore volume, and material diversity make mesoporous materials highly desirable for electrochemical applications., ${ }^{\mathbf{9}, 10}$ In particular, mesoporous metal lithiates (MMLs), such as $\mathrm{LiCoO}_{2}, \mathrm{LiMn}_{2} \mathrm{O}_{4}$, and $\mathrm{LiMn}_{2-x} \mathrm{Co}_{x} \mathrm{O}_{4}$, have been investigated as cathode materials in lithium ion batteries and as water oxidation electrocatalysts for water splitting. ${ }^{11-14}$ MMLs have generally been prepared via hard templating approaches, ${ }^{15-23}$ which use preformed mesoporous silica or carbon as hard templates to mimic their structures in metal oxides in the powder form. The demand is, however, always high for hierarchically structured porous films. Film quality becomes even more important if they are used as thin film electrodes for water splitting. ${ }^{24-27}$ Therefore, new soft-templating $^{28-31}$ (due to their applicability towards thin films)

${ }^{a}$ Department of Chemistry, Bilkent University, 06800, Ankara, Turkey.E-mail: dag@ fen.bilkent.edu.tr; karadas@fen.bilkent.edu.tr

${ }^{b}$ UNAM - National Nanotechnology Research Center, Institute of Materials Science and Nanotechnology, Bilkent University, 06800, Ankara, Turkey

$\dagger$ Electronic supplementary information (ESI) available. See DOI: 10.1039/c8ta04138e methods are necessary for the fabrication of hierarchically mesostructured film electrodes.

Molten salt-assisted self-assembly (MASA) ${ }^{32-35}$ is an effective soft-templating process to synthesize sponge like mesoporous thin films. Similar to evaporation induced self-assembly (EISA), ${ }^{36-38}$ a clear mixture of ingredients is coated over a substrate, followed by calcination at an elevated temperature in the MASA approach. The major difference, between the MASA and EISA processes, is that the salt species are in the molten phase and can be indefinitely kept in the mesophase (as a gel) in the MASA process. However, in the EISA process, the mesophase formed upon coating a solution of ingredients quickly transforms to a solid mesostructure, due to the polymerizing precursor(s) in the media. One obvious distinction is the formation of a stable lyotropic liquid crystalline (LLC) mesophase (gel phase) in the MASA versus a mesostructured solid through LLC in the EISA process. Therefore, EISA is limited to the synthesis of silica or metal oxides using their alkoxide precursors, which immediately transform to metal oxyhydroxide species, through hydrolysis and condensation reactions, and undergo self-assembly with surfactants. Since many transition metal precursors are salts that undergo hydrolysis and condensation reactions at elevated temperatures, MASA is more suitable than EISA for materials based on transition metals. 
For an effective soft-templating process, a molten saltsurfactant mesophase, with a very high salt content, is beneficial to synthesize stable mesoporous metal oxides. ${ }^{39}$ Note also that many transition metal salts ${ }^{\mathbf{4 0}}$ and lithium salts ${ }^{\mathbf{4 1}}$ form LLC mesophases with non-ionic surfactants at extremely high salt concentrations. More importantly, the cooperation of two salts that enhance the solubility of each other in the mesophase and two surfactants that stabilize the high salt content in the mesophase are key for the MASA process. We have recently introduced mesophases of lithium salt-cobalt salt-surfactants and lithium salt-manganese salt-surfactants that can be spin-coated and calcined into mesoporous transparent $\mathrm{LiCoO}_{2}$ and $\mathrm{LiMn}_{2} \mathrm{O}_{4}$ thin films. ${ }^{42}$ The role of the charged surfactant has been discussed in detail, and the synthetic strategies have been established using 10-lauryl ether and a charged surfactant (cetyltrimethylammonium bromide, CTAB, and cetyltrimethylammonium nitrate, CTAN). The water oxidation studies on these $\mathrm{LiCoO}_{2}$ thin films also indicate that they exhibit enhanced electrocatalytic performances compared to previous studies. ${ }^{\mathbf{4 3}-47}$

Since cobalt is more toxic and less earth-abundant compared to manganese, $\mathrm{LiMn}_{2} \mathrm{O}_{4}$ in the form of powder has also been investigated previously. ${ }^{4-47}$ Despite the promising electrocatalytic performances of MMLs, little effort has been devoted to investigating their long-term stabilities under real working conditions, e.g. at high current densities. Therefore, novel synthetic methods should be introduced to prepare robust electrodes, wherein the catalyst is strongly attached to the electrode surface.

In this contribution, P123 and CTAB were collectively used to assemble LLC mesophases to produce large pore, high surface area, high quality thin films of mesoporous $\mathrm{LiMn}_{2} \mathrm{O}_{4}$ and $\mathrm{LiMn}_{2-x} \mathrm{Co}_{x} \mathrm{O}_{4}$, and their electrochemical properties have been investigated as water oxidation electrocatalysts.

\section{Experimental}

\section{Synthesis of mesoporous $\operatorname{LiMn}_{2} \mathrm{O}_{4}\left(\right.$ meso-LiMn $\left.\mathrm{O}_{4}\right)$ by using P123/CTAB surfactant couples}

In a typical procedure, clear solutions of all ingredients were prepared by varying the total salt amount/P123 (30, 60 and 90) and CTAB/P123 (from 1 to 5) mole ratios. The amounts of $\mathrm{HNO}_{3}$ and $\mathrm{EtOH}$ were kept constant. As an example, the sample with a total salt amount/P123 of 60 and CTAB/P123 of 1 was prepared as follows. Firstly, $2.5 \mathrm{mmol}(173 \mathrm{mg})$ of $\mathrm{LiNO}_{3} \cdot x \mathrm{H}_{2} \mathrm{O}$ was dissolved in $5 \mathrm{~g}$ of EtOH. Afterwards, $0.125 \mathrm{mmol}$ (46 mg) of CTAB, $0.125 \mathrm{mmol}\left(719 \mathrm{mg}\right.$ ) of $\mathrm{P} 123,550 \mathrm{mg}$ of concentrated $\mathrm{HNO}_{3}$ $(70 \%)$ and $5 \mathrm{mmol}(1255 \mathrm{mg})$ of $\left[\mathrm{Mn}\left(\mathrm{H}_{2} \mathrm{O}\right)_{4}\right]\left(\mathrm{NO}_{3}\right)_{2}$ were sequentially added to the above clear solution with 5 min time intervals, and the solution was stirred overnight. Subsequently, 7 drops of the above clear solution were placed on every glass substrate to prepare thick films. The gel-like films were left for an hour to completely evaporate the ethanol and excess water to form the gel (gelation). Afterwards, the drop-cast films were placed into a preheated oven for calcination at $300{ }^{\circ} \mathrm{C}$ for $3 \mathrm{~h}$. Finally, the powder samples were collected for characterization by scraping the glass substrates.
Synthesis of mesoporous $\operatorname{LiMn}_{2-x} \mathrm{Co}_{x} \mathrm{O}_{4}$ (meso$\operatorname{LiMn}_{1-x} \mathrm{Co}_{x} \mathrm{O}_{4}$ ) powder by using the P123/CTAB couple

Three samples were prepared with two different $\mathrm{Mn}$ (II)/Co(II) ratios $(25,50$, and $75 \% \mathrm{Mn}$ (II) was replaced with $\mathrm{Co}(\mathrm{II}))$. The first sample was prepared as follows. Firstly, $2.5 \mathrm{mmol}(173 \mathrm{mg})$ of $\mathrm{LiNO}_{3} \cdot x \mathrm{H}_{2} \mathrm{O}$ was dissolved in $5 \mathrm{~g}$ of EtOH. Then with 5 min time intervals, $0.125 \mathrm{mmol}$ (46 mg) of CTAB, $0.125 \mathrm{mmol}(719 \mathrm{mg})$ of $\mathrm{P} 123,550 \mathrm{mg}$ of $\mathrm{HNO}_{3}, 3.75 \mathrm{mmol}(941 \mathrm{mg})$ of $\left[\mathrm{Mn}\left(\mathrm{H}_{2} \mathrm{O}\right)_{4}\right]\left(\mathrm{NO}_{3}\right)_{2}$ and $1.25 \mathrm{mmol}(364 \mathrm{mg})$ of $\left[\mathrm{Co}\left(\mathrm{H}_{2} \mathrm{O}\right)_{6}\right]\left(\mathrm{NO}_{3}\right)_{2}$ were sequentially added to the above clear solution, and the solution was stirred overnight. Subsequently, 7 drops of the above clear solution were put on several glass substrates to prepare thick films. The gelation process has been carried out for an hour. Afterwards, the dropcast films were placed into a preheated oven for calcination at 300 ${ }^{\circ} \mathrm{C}$ for $3 \mathrm{~h}$. After the calcination steps, the powder samples were obtained via scraping the glass substrates for characterization.

\section{Synthesis of MML thin films by using the P123/CTAB couple}

Clear ethanol solutions of all ingredients are prepared as described in the above procedures by varying the salt/P123 and CTAB/P123 mole ratios. 3 different salt (lithium nitrate and manganese and/or cobalt nitrates)/P123 compositions (30, 60, and 90 mole ratios) were selected as low, intermediate, and high salt contents, respectively, to form the clear solutions. Then, a few drops of the clear solution are put on a substrate over the spin coater and spun at various spin rates (500 to $2000 \mathrm{rpm}$ ) to form thin films of the LLC mesophase with various thicknesses. Finally, the films are calcined at an elevated temperature to obtain the MMLs.

\section{XRD measurements}

Thin film and powder X-ray diffraction (XRD) patterns were recorded by using a Rigaku Miniflex diffractometer, equipped with a Miniflex goniometer and an X-ray source with $\mathrm{Cu} \mathrm{K} \alpha$ radiation $(\lambda=1.5405 \AA$ ) operated at $30 \mathrm{kV}$ and $15 \mathrm{~mA}$. The XRD patterns of the thin films were collected between 1 and $5^{\circ}$ with a scan rate of $1^{\circ} \mathrm{min}^{-1}$. The powder samples were packed into standard glass sample holders, and the patterns were collected for $2 \theta$ values between 10 and $80^{\circ}$ with a scan rate of $1^{\circ} \mathrm{min}^{-1}$. The diffraction patterns were indexed using the Joint Committee on Powder Diffraction Standards (JCPDS) cards.

\section{$\mathbf{N}_{2}$ (77.4 K) sorption measurements}

Before the measurement, the samples were dehydrated at $473 \mathrm{~K}$ for $2 \mathrm{~h}$ in a vacuum. The $\mathrm{N}_{2}$ sorption isotherms were measured by using a TriStar 3000 automated gas adsorption analyzer (Micrometrics) in the relative pressure range, $P / P_{\mathrm{o}}$, from 0.01 to 0.99 . The saturated pressure was measured over intervals of 120 minutes. The surface areas of the different samples measured were calculated in the relative pressure range of 0.05 to 0.30 with 5 points.

\section{Polarized optical microscopy (POM) images}

The POM images were recorded by using a ZEISS Axio Scope A1 polarizing optical microscope in transmittance mode for the films, coated over glass slides. 


\section{FT-IR measurements}

The FT-IR spectra were recorded using a Bruker Tensor 27 model FT-IR spectrometer. A Digi Tect TM DLATGS detector was used with a resolution of $4.0 \mathrm{~cm}^{-1}$ in the range from $400 \mathrm{~cm}^{-1}$ to $4000 \mathrm{~cm}^{-1}$. The data obtained after 64 scans were recorded using films, coated over IR transparent silicon wafers.

\section{Micro-Raman measurements}

A LabRam confocal Raman microscope with a $300 \mathrm{~mm}$ focal length has been used for the measurements. The device has a Ventus LP 532, $50 \mathrm{~mW}$, diode pumped solid-state laser operated at 20 to $34 \mathrm{~mW}$ with a polarization ratio of $100: 1$, a wavelength of $532.1 \mathrm{~nm}$ and a $1024 \times 256$ element CCD camera. The signal collected was transmitted via a fiber optic cable into the spectrometer with a $600 \mathrm{~g} \mathrm{~mm}^{-1}$ grating. The Raman spectra of the samples were recorded by placing the probe tip on the desired point of the sample over the glass slide or silicon wafer.

\section{TEM analysis}

A homogenized solution of the required sample was spin coated over a glass substrate at $5000 \mathrm{rpm}$ for 20 seconds to obtain a very thin film. Then the film was calcined at a desired temperature and duration, scraped from the substrate, and then placed in a solution of ethanol and sonicated for $30 \mathrm{~min}$ to disperse the particles. The dispersed mixture was dropped on a carbon coated $\mathrm{Cu}$ grid with a 300 mesh under an UV lamp. The dried grid was placed in a transmission electron microscope (TEM) (FEI Technai G2) at an operating voltage of $200 \mathrm{kV}$.

\section{SEM images}

The SEM images and the EDS data were obtained using an FEIQuanta 200 FEG ESEM and a Zeiss EVO-40 SEM operating at 15 $\mathrm{kV}$ and a Bruker AXS XFlash detector 4010 attached to the same microscope using the same samples.

\section{Electrochemical studies}

A conventional three-electrode electrochemical cell was used with an $\mathrm{Ag} / \mathrm{AgCl}$ electrode $(3.5 \mathrm{M} \mathrm{KCl})$ as the reference electrode, Pt wire as the counter electrode, and catalyst modified fluorine doped tin oxide (FTO) substrate as the working electrode. A 1 M $\mathrm{KOH}$ solution was used under alkaline conditions ( $\mathrm{pH}$ 13.6). Cyclic voltammograms (CV) were recorded with a scan rate of 50 $\mathrm{mV} \mathrm{s}^{-1}$ between $0 \mathrm{~V}$ and $1.5 \mathrm{~V}(v s . \mathrm{Ag} / \mathrm{AgCl})$. All experiments were carried out under a nitrogen atmosphere. The $\mathrm{pH}$ of the solution was measured with a Mettler Toledo $\mathrm{pH}$ meter (S220).

\section{Results and discussion}

\section{Synthesis and characterization of the meso- $\operatorname{LiMn}_{2} \mathrm{O}_{4}$ and $\mathrm{LiMn}_{1-x} \mathrm{Co}_{x} \mathrm{O}_{4}$ thin films}

The first step in the synthesis of MMLs is to prepare homogeneous solutions using salt-surfactant ingredients. All ingredients, namely, surfactants (P123 and CTAB) and salts $\left(\mathrm{LiNO}_{3}\right.$ and $\left[\mathrm{Mn}\left(\mathrm{H}_{2} \mathrm{O}\right)_{4}\right]\left(\mathrm{NO}_{3}\right)_{2}$ and/or $\left.\left[\mathrm{Co}\left(\mathrm{H}_{2} \mathrm{O}\right)_{6}\right]\left(\mathrm{NO}_{3}\right)_{2}\right)$ are dissolved in ethanol and stirred until clear solutions are obtained. Then, the clear solutions are coated by either spin coating or drop casting to form a mesophase (as a gel film, see Fig. 1). The precursor solutions are indefinitely stable in the solution phase in the presence of a small amount of acid, and the gel-films are stable for long periods of time, depending on the salt content (see latter). The MASA assembly process and further heat treatments are schematically shown in Fig. 1.

In this work, we investigated three different salt contents (30, 60 , and 90 salt/P123 mole ratios) by varying the CTAB/P123 mole ratio (1-5) at all stages of the process. Note also that the MASA process used in this assembly has been investigated in detail in our previous work using an oligo (ethylene oxide) type non-ionic surfactant (10-lauryl ether, $\left.\mathrm{C}_{12} \mathrm{E}_{10}\right) \cdot{ }^{42}$ Here, we optimized our synthesis conditions using P123 to take advantage of the larger surfactant in the assembly process. Like the 10-lauryl ether system, in the presence of CTAB, a color change occurs during homogenization of the solutions in the P123 system, yellow in $\mathrm{Mn}$ (II) and blue in Co(II) systems. The colors originate from the formation of $\left[\mathrm{MnBr}_{4}\right]^{2-}$ and $\left[\mathrm{CoBr}_{4}\right]^{2-}$ species in the solution. ${ }^{42}$ In the 10-lauryl ether system, we also synthesized CTAN (cetyltrimethylammonium nitrate) and used it in place of CTAB to prevent the formation of metal bromide complex ions that undergo phase separation by forming (CTA $)_{2}\left[\mathrm{MBr}_{4}\right]$ crystals. $^{42}$ However, the formation of these species is not problematic in the Mn(II) system in both 10-lauryl ether and P123 systems. Moreover, the synthesis of CTAN is expensive and tedious. ${ }^{48}$ Therefore, only CTAB has been used throughout this investigation. Note also that the charged surfactant is necessary in the MASA process to accommodate such high salt concentrations in their molten state in the mesophase. ${ }^{\mathbf{4 0}}$ Therefore, the optimization has been carried out only to determine the salt/P123 and $\mathrm{CTAB} / \mathrm{P} 123$ mole ratios to find the composition of stable LLC mesophases.

The spin-coated films are indefinitely stable in the lyotropic liquid crystalline mesophase at room temperature, if the salt/ surfactant ratios are properly adjusted. The drop casting method is also useful to produce large quantities of the samples as monoliths and powders. The only issue, in drop casting, could be observed in the gelation step, where the volatile solvent (ethanol) evaporates completely to form the gels. During evaporation of the solvent, salt crystallization may occur. Therefore,

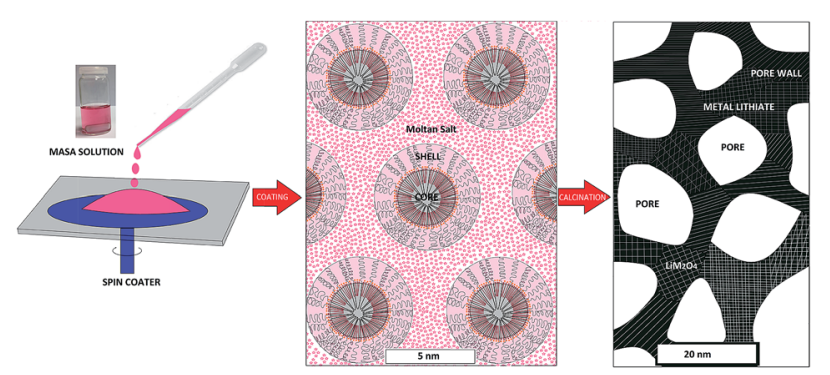

Fig. 1 Schematic representation of the MASA process and formation of mesoporous MMLs. CORE and SHELL are surfactant domains, hydrophobic polypropylene oxide blocks and hydrophilic polyethylene oxide blocks in the LLC phase, respectively. 
one must ensure there is neither salt nor $(\mathrm{CTA})_{2}\left[\mathrm{MBr}_{4}\right]$ crystallization in the LLC phase before calcination. To resolve and elucidate this crystallization issue, a set of fresh samples were analyzed using both small/wide angle XRD and POM imaging. The fresh LLC samples display sharp lines in their XRD patterns at small angles in all three compositions (Fig. 2). Fig. S1† shows the XRD patterns of the fresh samples by varying the CTAB/P123 mole ratio using 60 salt/P123 samples. With increasing CTAB in the media, the diffraction line gradually shifts to higher angles, indicating shrinkage of the unit cells. This is a known behavior in salt-surfactant mesophases in the presence of CTAB. ${ }^{49}$ Our previous work showed that increasing the amount of CTAB shrinks the unit cell; however increasing the amount of salt enlarges the unit cell in the mesophase. ${ }^{49}$ Therefore, the charged surfactant content of the mesophase determines the volume of the hydrophilic domains of the mesophase for the salt species; for samples with higher salt concentrations, the CTAB amount should be further increased to obtain a stable mesophase. Therefore, at high salt concentrations, the CTAB/ P123 needs to be optimized. We did the CTAB optimization using the 60 salt/P123 samples and found out that up to $5 \mathrm{CTAB} /$ $\mathrm{P} 123$, no CTAB or (CTA $)_{2}\left[\mathrm{MnBr}_{4}\right]$ crystallization was observed in the gel-phase; thus, further investigation was carried out using 60 salts, 5 CTAB and $1 \mathrm{P} 123$ ratios. Also, note that the formation of the $(\mathrm{CTA})_{2}\left[\mathrm{CoBr}_{4}\right]$ and $(\mathrm{CTA})_{2}\left[\mathrm{MnBr}_{4}\right]$ complex surfactant salts could be an issue during the calcination step to form bulk metal oxides and metal bromides (stable at our calcination temperatures) on the surface of the films. The (CTA $)_{2} \mathrm{MBr}_{4}$ salts ( $\mathrm{M}$ is either $\mathrm{Co}(\mathrm{II})$ or $\mathrm{Mn}(\mathrm{II})$ ) first burn into metal bromides $\left(\mathrm{MBr}_{2}\right)$ and then to metal oxides at elevated temperatures, such as $600{ }^{\circ} \mathrm{C}$ and above. Therefore, their formation is undesirable during the gelation and heating steps.

The spin coated and drop cast LLC film and monolithic samples, respectively, were calcined at temperatures as low as $300{ }^{\circ} \mathrm{C}$. The calcination produces disordered mesoporous nanocrystalline $\mathrm{LiMn}_{2} \mathrm{O}_{4}$ at all ratios (see Fig. S2 and 3 ) $\cdot \dagger$ However, the surface area of the sample, prepared using 60 salts $\left(20 \mathrm{LiNO}_{3}+40\left[\mathrm{Mn}\left(\mathrm{H}_{2} \mathrm{O}\right)_{4}\right]\left(\mathrm{NO}_{3}\right)_{2} / \mathrm{P} 123\right)$, is relatively larger $\left(98 \mathrm{~m}^{2} \mathrm{~g}^{-1}\right)$ than those of both $30\left(60 \mathrm{~m}^{2} \mathrm{~g}^{-1}\right)$ and 90 $\left(68 \mathrm{~m}^{2} \mathrm{~g}^{-1}\right)$ samples (see Fig. S4). $\uparrow$ Therefore, further investigations were carried out using a 60 salt/P123 mole ratio in further steps of the optimization of the synthesis conditions.

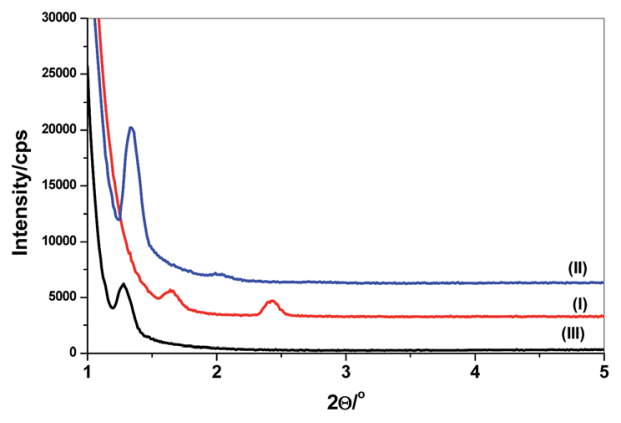

Fig. 2 Small angle XRD patterns of the fresh samples of (a) (I) 30, (II) 60 , and (III) $90\left(\mathrm{LiNO}_{3}+\left[\mathrm{Mn}\left(\mathrm{H}_{2} \mathrm{O}\right)_{4}\right]\left(\mathrm{NO}_{3}\right)_{2}\right) / \mathrm{P} 123$ mole ratios.
Fig. S2 and $3 \dagger$ show a set of the XRD patterns and Barrett-Joyner-Halenda $(\mathrm{BJH})$ pore size distribution plots (obtained from the $\mathrm{N}_{2}$ desorption branch) of the same samples, prepared by the drop casting method, respectively. The XRD patterns, recorded for the samples calcined at 300 to $650{ }^{\circ} \mathrm{C}$, can be indexed to the spinel $\mathrm{LiMn}_{2} \mathrm{O}_{4}$ phase. No other crystalline impurities were detected up to $500{ }^{\circ} \mathrm{C}$. However, a new set of sharp diffraction lines appear at $2 \theta$ values of $32.9^{\circ}$ and $55.1^{\circ}$ above $500{ }^{\circ} \mathrm{C}$. These lines correspond to the (222) and (440) planes of $\mathrm{Mn}_{2} \mathrm{O}_{3}$ crystals, which are a decomposition product of $\mathrm{LiMn}_{2} \mathrm{O}_{4}$. Notice also that the diffraction lines of the $\mathrm{LiMn}_{2} \mathrm{O}_{4}$ get sharper at elevated temperatures, also indicating growth of the $\mathrm{LiMn}_{2} \mathrm{O}_{4}$ phase. Raman spectra also verify the formation of $\mathrm{LiMn}_{2} \mathrm{O}_{4}$ and its decomposition to $\mathrm{Mn}_{3} \mathrm{O}_{4}{ }^{50}$ (Fig. S5). $\dagger$ During the Raman measurements, the sample undergoes thermal decomposition under a powerful laser beam to form manganese oxides. ${ }^{50,51}$ For instance, the peak at $625 \mathrm{~cm}^{-1}$ and the weaker peaks on the low energy side originate from the $\mathrm{Mn}_{3} \mathrm{O}_{4}$ phase, which is the high temperature decomposition product of $\mathrm{LiMn}_{2} \mathrm{O}_{4} \cdot{ }^{51}$ Notice that the diffraction lines get shaper and the pore size increases as the annealing temperature increases from 300 to $650{ }^{\circ} \mathrm{C}$, indicating crystallization and growth of the pore-walls (see Fig. S2 and 3$) ; \uparrow$ the pore size increases from 10 to $30 \mathrm{~nm}$ (calculated from the desorption branch using the $\mathrm{BJH}$ model), and the surface area decreases from 100 to $18 \mathrm{~m}^{2} \mathrm{~g}^{-1}$ (calculated from the Brunauer-Emmett-Teller (BET) analysis method) with annealing (see Table 1).

We also prepared a set of samples using both metal salts (Co(II) and $\mathrm{Mn}(\mathrm{II})$ ), by adding cobalt into the $\mathrm{LiMn}_{2} \mathrm{O}_{4}$ system, to synthesize $\mathrm{LiMn}_{2-x} \mathrm{Co}_{x} \mathrm{O}_{4}$. There is no difference in the mesophases (fresh samples) of 2 and 3 salt systems. Calcination of the mesophases produce thin films of transparent/high quality mesoporous $\mathrm{LiMn}_{2-x} \mathrm{Co}_{x} \mathrm{O}_{4}$ (denoted as meso- $\mathrm{LiMn}_{2-x} \mathrm{Co}_{x} \mathrm{O}_{4}$ ). Fig. 3(b) and 4 show a set of $\mathrm{N}_{2}$ adsorption-desorption isotherms and XRD patterns of these samples, calcined at $300{ }^{\circ} \mathrm{C}$, respectively.

Interestingly, all the samples diffract exactly like pure spinel $\mathrm{LiMn}_{2} \mathrm{O}_{4}$ with relatively broader lines and a small shift to higher angles which is consistent with homogeneous incorporation of Co(III) to the spinel structure (see Fig. 4). The typical particle size, obtained from the Scherrer equation $(\sim 5-6 \mathrm{~nm})$, is also consistent with the increased surface area and broadening of

Table $1 \mathrm{~N}_{2}$ adsorption-desorption data of the selected samples (CT = calcination temperature, $\mathrm{SA}=$ surface area, $\mathrm{PS}=$ pore size, and $\mathrm{PV}=$ pore volume)

\begin{tabular}{|c|c|c|c|c|}
\hline Samples & $\begin{array}{l}\mathrm{CT} \\
\left({ }^{\circ} \mathrm{C}\right)\end{array}$ & $\begin{array}{l}\text { BET SA } \\
\left(\mathrm{m}^{2} \mathrm{~g}^{-1}\right)\end{array}$ & $\begin{array}{l}\text { BJH PS } \\
(\mathrm{nm})\end{array}$ & $\begin{array}{l}\text { PV } \\
\left(\mathrm{cm}^{3} \mathrm{~g}^{-1}\right)\end{array}$ \\
\hline meso- $\mathrm{LiMn}_{2} \mathrm{O}_{4}$ & 300 & 98 & 11.1 & 0.26 \\
\hline meso-LiMn ${ }_{2} \mathrm{O}_{4}$ & 400 & 90 & 10.8 & 0.25 \\
\hline meso-LiMn ${ }_{2} \mathrm{O}_{4}$ & 500 & 69 & 12.9 & 0.28 \\
\hline meso-LiMn ${ }_{2} \mathrm{O}_{4}$ & 600 & 33 & 22.5 & 0.24 \\
\hline meso-LiMn ${ }_{1.5} \mathrm{Co}_{0.5} \mathrm{O}_{4}$ & 300 & 144 & 6.7 & 0.27 \\
\hline meso-LiMnCoO & 300 & 124 & 6.6 & 0.23 \\
\hline meso-LiMn ${ }_{0.5} \mathrm{Co}_{1.5} \mathrm{O}_{4}$ & 300 & 103 & 5.7 & 0.17 \\
\hline
\end{tabular}



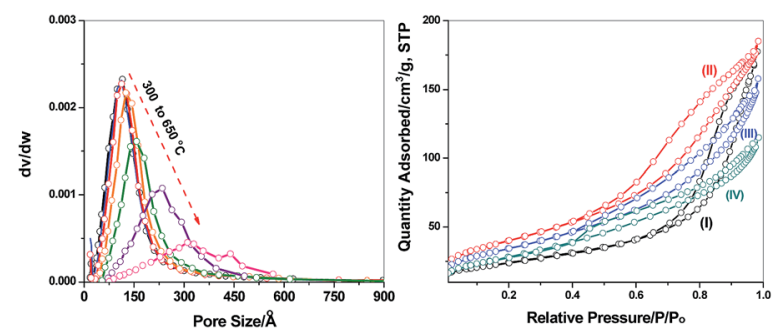

Fig. 3 (Left) $\mathrm{BJH}$ pore-size distribution (from the $\mathrm{N}_{2}$ desorption branch) plots of meso- $\mathrm{LiMn}_{2} \mathrm{O}_{4}$, calcined at $300-650{ }^{\circ} \mathrm{C}$, top to bottom, and (right) $\mathrm{N}_{2}$ adsorption-desorption isotherms of $\mathrm{LiMn}_{2-x^{-}}$ $\mathrm{CO}_{x} \mathrm{O}_{4}$, calcined at $300^{\circ} \mathrm{C}$. $x$ is (I) 0.0 , (II) 0.5 , (III) 1.0 , and (IV) 1.5 .

the diffraction lines in the mixed oxides (see latter). The spinel structure of $\mathrm{LiMn}_{2} \mathrm{O}_{4}$ is kept in the mixed compounds, $\mathrm{LiMn}_{2-x} \mathrm{Co}_{x} \mathrm{O}_{4}$ with $x$ up to $1.0 .^{52,53}$ However, the diffraction patterns of the meso- $\mathrm{LiMn}_{2-x} \mathrm{Co}_{x} \mathrm{O}_{4}$ with an $x$ of 1.5 and above show changes from the typical patterns of spinel $\mathrm{LiMn}_{2} \mathrm{O}_{4}$, indicating that the $\mathrm{Co}(\mathrm{III})$ uptake limit of the spinel meso$\mathrm{LiMn}_{2} \mathrm{O}_{4}$ is around 1.0.52,53

The $\mathrm{N}_{2}$ adsorption-desorption plots of the meso- $\mathrm{LiMn}_{2-x^{-}}$ $\mathrm{Co}_{x} \mathrm{O}_{4}$ films display type IV isotherms with hysteresis, characteristic of mesoporous materials (see Fig. 3). The BET surface area is larger in the meso- $\mathrm{LiMn}_{2-x} \mathrm{Co}_{x} \mathrm{O}_{4}$; surface areas as high as 144 and $124 \mathrm{~m}^{2} \mathrm{~g}^{-1}$ were recorded for the samples, in which $x$ is 0.5 and 1.0, respectively, (see Table 1). The synergic effects of the two salts (enhanced solubility of the salts together with better surfactant-salt interactions) during the initial synthesis stage improved pore-walls (pore size dropped from 11 to around $6 \mathrm{~nm}$ ) and enhanced the surface area in the mixed oxide cases.

The formation of mixed oxides has also been verified by FTIR and Raman spectroscopy. The FTIR spectra of the $\operatorname{LiMn}_{2-x^{-}}$ $\mathrm{Co}_{x} \mathrm{O}_{4}$ samples display $\mathrm{Mn}-\mathrm{O}$ and $\mathrm{Co}-\mathrm{O}$ stretching related peaks at 500 and 618 , and 566 and $660 \mathrm{~cm}^{-1}$, respectively, (see Fig. 5), and a gradual blue-shift of the peaks, with increasing the cobalt content of the samples, is a good indication of homogeneous mixing of $\mathrm{Mn}$ (III) and $\mathrm{Co}$ (III) in the final products. The blue shift in the FTIR spectra and the gradual small shifts of the diffraction lines to higher angles in the XRD patterns indicate

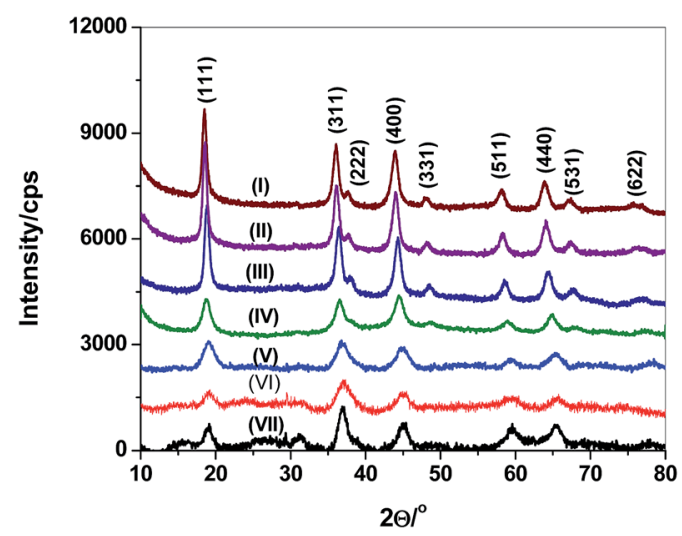

Fig. 4 XRD patterns of the meso- $\mathrm{LiMn}_{2-x} \mathrm{CO}_{x} \mathrm{O}_{4}$ calcined at $300{ }^{\circ} \mathrm{C} . x$ is (I) 0.0, (II) 0.02, (III) 0.1, (IV) 0.5, (V) 1.0, (VI) 1.5, and (VII) 2.0.

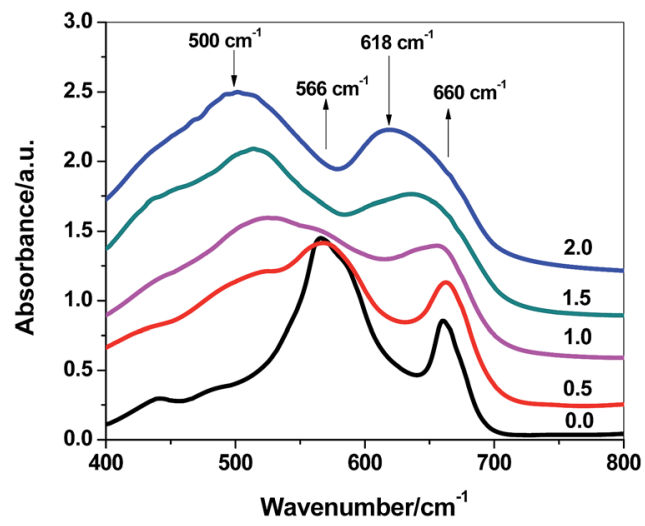

Fig. 5 FTIR spectra of $\mathrm{LiMn}_{2-x} \mathrm{CO}_{x} \mathrm{O}_{4}$ with increasing $x$; from top to bottom $x$ is $2.0,1.5,1.0,0.5$, and 0.0 .

shorter/stronger Co-O bonds, compared to $\mathrm{Mn}-\mathrm{O}$ bonds, in the $\mathrm{LiMn}_{2-x} \mathrm{Co}_{x} \mathrm{O}_{4}$. As mentioned above, one must be very careful with the Raman measurements. Both $\mathrm{LiMn}_{2} \mathrm{O}_{4}$ and $\mathrm{LiMn}_{2-x^{-}}$ $\mathrm{Co}_{x} \mathrm{O}_{4}$ crystallites are very sensitive to the laser exposure time and power, ${ }^{51}$ such that they undergo laser induced thermal decomposition to $\mathrm{Mn}_{3} \mathrm{O}_{4}$ in the manganese rich samples and $\mathrm{Co}_{3} \mathrm{O}_{4}$ in the cobalt rich samples. The sharp and most intense peaks at 625 and $670 \mathrm{~cm}^{-1}$, corresponding to the $\mathrm{Mn}_{3} \mathrm{O}_{4}$ and $\mathrm{Co}_{3} \mathrm{O}_{4}$ crystallites, respectively, appear during focusing of the laser beam (see Fig. S5) $\dagger$

Fig. 6 (top) shows 5 photographs of the mesoporous $\mathrm{LiMn}_{2-x} \mathrm{Co}_{x} \mathrm{O}_{4}$ films over FTO glass substrates. The meso$\mathrm{LiMn}_{2} \mathrm{O}_{4}$ and meso-LiMn ${ }_{2-x} \mathrm{Co}_{x} \mathrm{O}_{4}$ films have high optical quality. The color of the films changes from brown to darkgreen with increasing cobalt in the samples (see Fig. 6 (top)). We also collected the SEM and TEM images of the meso- $\mathrm{LiMn}_{2} \mathrm{O}_{4}$ and $m e s o-\mathrm{LiMn}_{2-x} \mathrm{Co}_{x} \mathrm{O}_{4}$ thin films to show the film quality in the next two length scales (micron to nanometer) and the pore system. Fig. 6a and b show two SEM images of the films coated over FTO substrates. The SEM images display large and small uniform pores in the films. The likely origin of the large pores is the aggressive evaporation of the volatile species (water and nitrate decomposition species) in the gel-phase during the calcination process. Note also that major water and nitrate species disappear before surfactants start burning. Smaller pores form upon burning surfactant species from the mesostructure. The TEM images also display uniform crystalline nanoparticles of $\mathrm{LiMn}_{2} \mathrm{O}_{4}$ and $\mathrm{LiMn}_{2-x} \mathrm{Co}_{x} \mathrm{O}_{4}$ (Fig. 6c, d and $\mathrm{S} 6 \dagger$ ) that were also confirmed by the EDS spectra (Fig. S7 $\dagger$ ) of the samples. The nanoparticles are crystalline and display lattice fringes corresponding to the (111) plane of $\mathrm{LiMn}_{2} \mathrm{O}_{4}$ and $\mathrm{LiMn}_{1.5} \mathrm{Co}_{0.5} \mathrm{O}_{4}$ (see Fig. 6d). It corresponds to the most intense line in the XRD pattern of meso- $\mathrm{LiMn}_{2} \mathrm{O}_{4}$. Detailed analysis of the TEM image shows that $\mathrm{LiMn}_{2-x} \mathrm{Co}_{x} \mathrm{O}_{4}$ crystallize preferentially along the [111] direction. Both SEM and TEM images (Fig. 6) show that the $\mathrm{LiMn}_{2-x} \mathrm{Co}_{x} \mathrm{O}_{4}$ nanocrystallites and pores are smaller than those of pure $\mathrm{LiMn}_{2} \mathrm{O}_{4}$; this is also consistent with the higher surface area in the mixed oxides. Therefore, the synergic effect of the two salts not only enhances the salt up take 

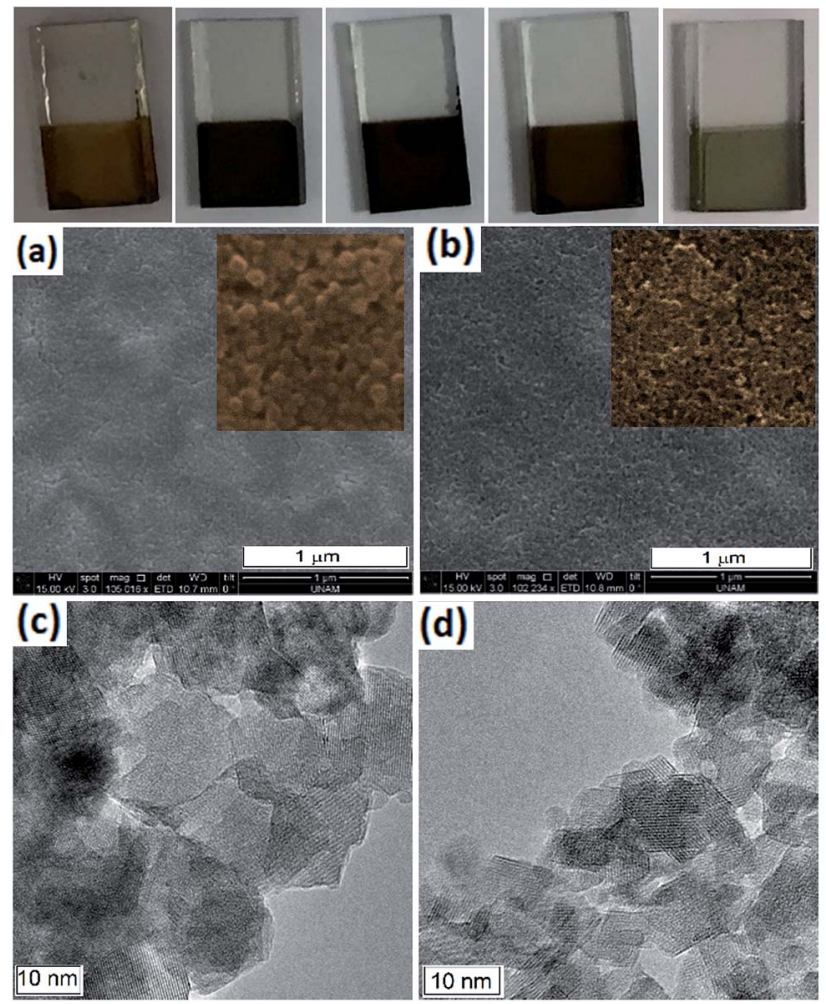

Fig. 6 (Top) photographs of the meso- $\mathrm{LiMn}_{2-x} \mathrm{Co}_{x} \mathrm{O}_{4}$ films over FTO glass substrates $(1 \mathrm{~cm} \times 1 \mathrm{~cm})$; from left to right $x$ is $2.0,1.5,1.0,0.5$, and 0.0. SEM images of meso- $\mathrm{LiMn}_{2} \mathrm{O}_{4}$ (a) and meso- $\mathrm{LiMn}_{1.5} \mathrm{Co}_{0.5} \mathrm{O}_{4}$ (b); the insets are the magnified images of the samples. TEM image (c) and HRTEM image (d) of the meso- $\mathrm{LiMn}_{2} \mathrm{O}_{4}$ films.

of the mesophases, but also affects the nucleation and growth of the $\mathrm{LiMn}_{2-x} \mathrm{Co}_{x} \mathrm{O}_{4}$ pore-walls in the final product.

\section{Electrocatalysis of the meso- $\mathrm{LiMn}_{2} \mathrm{O}_{4}$ and meso- $\operatorname{LiMn}_{1-x} \mathrm{Co}_{x} \mathrm{O}_{4}$ thin films for water oxidation}

The electrochemical properties of the meso- $\mathrm{LiMn}_{2} \mathrm{O}_{4}$ and meso$\mathrm{LiMn}_{1-x} \mathrm{Co}_{x} \mathrm{O}_{4}$ thin films, prepared over the FTO electrodes, were evaluated via cyclic voltammetry (CV) with a scan rate of 50 $\mathrm{mV} \mathrm{s}^{-1}$ in alkaline solution ( $\mathrm{pH} 13.6$ ) between -0.5 and $1.0 \mathrm{~V}$ (vs. NHE) (Fig. 7a). All CVs exhibit similar profiles with an irreversible feature at $c a .650 \mathrm{mV}$, indicative of the catalytic water oxidation process. Furthermore, a quasi-reversible peak, which is located at $\sim 500 \mathrm{mV}$, is observed. Since this peak is absent only in the $\mathrm{CV}$ of $\mathrm{LiMn}_{2} \mathrm{O}_{4}$, it is attributed to the $\mathrm{Co}^{2+/ 3+}$ redox process. As shown in Fig. $7 \mathrm{a}$, the catalytic current for $\mathrm{LiMn}_{2} \mathrm{O}_{4}$ at high positive potentials is lower compared to that of other derivatives, which suggests that cobalt sites are more active catalytic sites than manganese ones for water oxidation.

The slope of the peak current intensity and scan rate plot was extracted for the redox process to assess the surface concentration of cobalt ions for the electrodes (Fig. S8 $\dagger$ ). The results are summarized in Table 2. Interestingly, $\mathrm{LiMn}_{0.5} \mathrm{Co}_{1.5} \mathrm{O}_{4}(75 \%$ cobalt) exhibits a higher cobalt surface concentration than lithium cobaltate although the former has fewer cobalt ions per formula unit than the latter. The surface concentrations of
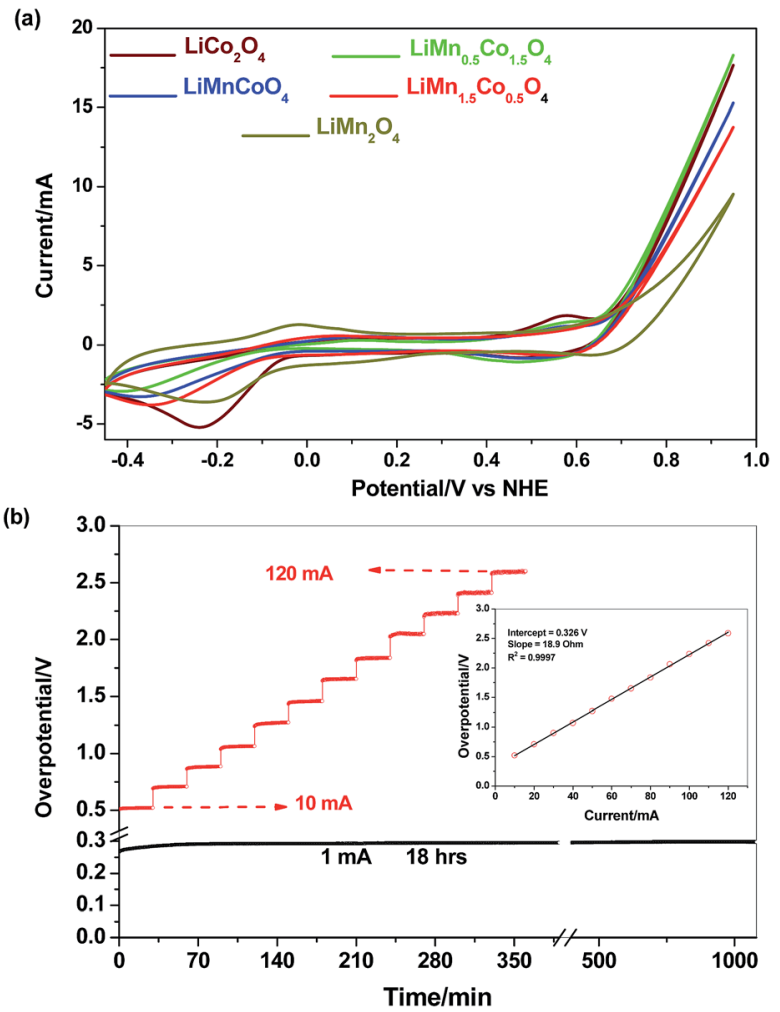

Fig. 7 (a) CV curves of the mesoporous $\mathrm{LiMn}_{1-x} \mathrm{Co}_{x} \mathrm{O}_{4}$ thin films and (b) chronopotentiometry experiment results of the mesoporous $\mathrm{LiMnCoO}_{4}$ thin film in the $1-120 \mathrm{~mA} \mathrm{~cm}{ }^{-2}$ range for $18 \mathrm{~h}$ (at $1 \mathrm{~mA}$ ), followed by $30 \mathrm{~min}$ at each increasing $10 \mathrm{~mA}$ interval up to $120 \mathrm{~mA}$. The inset shows the potential versus current plot in the 10-120 mA range.

$\mathrm{LiCoO}_{2}$ and $\mathrm{LiMnCoO}_{4}$ are also comparable. This trend in surface concentrations suggests that the substitution of the cobalt sites with manganese leads to an apparent increase in the number of electroactive cobalt sites on the surface, which compensates for the loss of cobalt atoms due to substitution with the manganese sites.

The effect of manganese sites on the surface concentration of the cobalt ions could, thus, be attributed to the change either in the morphology of the electrode surface or in the electronic properties of the catalyst, or a combination of both. The comparison of the surface area analyses of the samples indicates that the mixed metal lithiates have higher surface areas than the pure ones, which is in line with the trend in the surface concentration.

Chronoamperometric and chronopotentiometric studies were performed to investigate the effect of manganese atoms on the electronic properties of the electroactive cobalt sites and also to assess their electrocatalytic performances in detail. Like the CVs, the Tafel plot for $\mathrm{LiMn}_{2} \mathrm{O}_{4}$ differs significantly from those of the other compounds. Meso- $\mathrm{LiMn}_{2} \mathrm{O}_{4}$ exhibits a higher Tafel slope (124 mV dec ${ }^{-1}$ ) than the other catalysts $(60-70 \mathrm{mV}$ $\mathrm{dec}^{-1}$ range), which can be attributed to different catalytic mechanisms (Fig. S9†). The slopes, obtained for the meso$\mathrm{LiMn}_{x} \mathrm{Co}_{2-x} \mathrm{O}_{4}$ compounds, are in good accordance with those reported for mesoporous $\mathrm{LiCoO}_{2}$ samples in our previous 
Table 2 Summary of OER activities

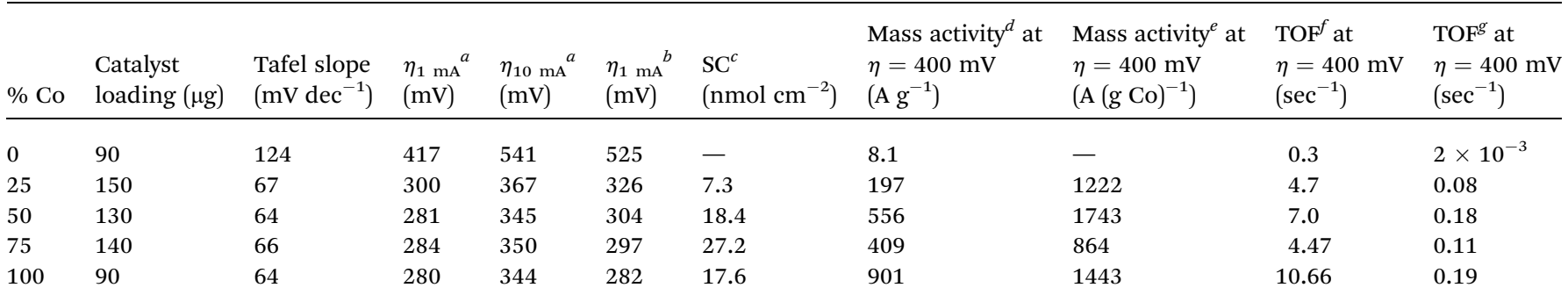

${ }^{a}$ Overpotentials extracted from Tafel plots. ${ }^{b}$ Overpotentials obtained from chronopotentiometry experiments. ${ }^{c}$ Surface concentration (SC) of cobalt ions. ${ }^{d}$ Mass activity calculated based on the Tafel plot and catalyst loading. ${ }^{e}$ Mass activity based on the Tafel plot and the amount of cobalt in the electrode. ${ }^{f}$ TOF calculated using the surface concentration. ${ }^{g}$ TOF calculated using catalyst loading.

study. ${ }^{42}$ The overpotentials extracted from the Tafel plots for current densities of 1 and $10 \mathrm{~mA} \mathrm{~cm}^{-2}$ are given in Table 2 . The lithium cobaltate electrode requires overpotentials of 280 and $344 \mathrm{mVs}$ at 1 and $10 \mathrm{~mA} \mathrm{~s}$, respectively. Chronopotentiometric experiments performed at a current density of $1 \mathrm{~mA} \mathrm{~cm}-2$ exhibit similar overpotentials (Fig. S10 $\dagger$ and Table 2). An initial increase in the overpotential is observed for each electrode, which is also reflected in the CVs performed before and after chronopotentiometric experiments (Fig. S11†). This profile is also in agreement with previous results. It is interesting to note that the overpotentials for $\mathrm{LiMn}_{0.5} \mathrm{Co}_{1.5} \mathrm{O}_{4}$ and $\mathrm{LiMnCoO}_{4}$ are maintained in the same range, which shows that similar electrocatalytic performance can be achieved with fewer than half the cobalt atoms in the assembly, thanks to the effect of the manganese ions on the morphology of the compounds. The meso- $\mathrm{LiMn}_{1.5} \mathrm{Co}_{0.5} \mathrm{O}_{4}$ electrode, although similar, requires slightly higher overpotentials than the other three derivatives. The overpotentials obtained for meso- $\mathrm{LiMn}_{2} \mathrm{O}_{4}$, however, are much higher, as expected from the Tafel plots.

Several different approaches have been adopted in the literature to report the turnover frequencies (TOF) of heterogeneous electrocatalysts, which differ mainly based on the estimation of the number of catalytic sites. ${ }^{54,55}$ TOFs in this study were first determined using the surface concentration of the catalysts, which has been previously used for cobalt based systems. ${ }^{56-58}$ The meso- $\mathrm{LiMn}_{2} \mathrm{O}_{4}$ has a much lower TOF than the other catalysts as predicted from CV studies. TOFs per cobalt atom were also obtained using the catalyst loading (lower bound TOF), which shows a similar trend (Fig. S12†). The similarity of the TOFs for the cobalt sites in the different electrodes indicates that manganese substitution has a prominent effect on the morphology rather than the electronic properties of the surface cobalt species.

The meso- $\mathrm{LiMn}_{x} \mathrm{Co}_{2-x} \mathrm{O}_{4}$ modified electrodes with $x \leq 1$ exhibit remarkable mass activities $\left(\mathrm{A} \mathrm{g}^{-1}\right)$ ranging from 400 to $901 \mathrm{~A} \mathrm{~g}^{-1}$, which are approximately 100 times higher compared to those of lithium cobaltates prepared via a conventional solgel procedure. ${ }^{18}$ The highest mass activity per cobalt is obtained for the meso- $\mathrm{LiMnCoO}_{4}$, which indicates that 50\% manganese substitution yields the optimum catalyst. The exceptional enhancement in the catalytic activity is mainly a result of the MASA process, which produces high quality catalysts with a mesoporous nature, a high surface area, and high durability. The robustness of the electrodes was also confirmed by chronopotentiometric studies, in which the current density was incrementally increased by $10 \mathrm{~mA}$ up to $120 \mathrm{~mA}$ (see Fig. 7b) using the meso-LiMnCoO${ }_{4}$ electrode that was previously used for $18 \mathrm{~h}$ at $1 \mathrm{~mA} \mathrm{~cm}{ }^{-2}$ chronopotentiometric measurements. A constant potential is maintained at each step, which clearly indicates that the catalyst retains its catalytic activity even under extremely harsh catalytic conditions (see the Movie in the ESI $\dagger$ section).

As shown in the inset of Fig. 7b, the apparent overpotential at constant current is a linear function of the applied current. This indicates that the added potential might be purely ohmic. In order to investigate this phenomenon further, similar experiments were carried out with positive feedback IR compensation. The uncompensated resistance was measured for every electrode using impedance spectroscopy, and cyclic voltammetry was performed while compensating for the resistance measured. These data are shown in Fig. S13. $\dagger$ With the IR compensated CV measurements, the activity trends towards water oxidation are free of any complications due to the resistance of the FTO support. Therefore, the current response in the 0.8-1.0 $\mathrm{V}$ range is a clear indication of the activity trends (Fig. S11†). The data indicate that the activity of the catalyst increases with the increasing cobalt amount if manganese is present inside the structure. The structures with no manganese and the composition of equimolar cobalt and manganese show roughly equal activities with half the cobalt amount.

\section{Conclusions}

The MASA process has been successfully adopted using P123 and CTAB for the synthesis of mesoporous $\mathrm{LiMn}_{2} \mathrm{O}_{4}$ and $\mathrm{LiMn}_{2-x} \mathrm{Co}_{x} \mathrm{O}_{4}$ thin films. These films have high quality (optical and resistance to the electrolyte during the electrocatalysis) with uniform mesoporosity. Larger pores form upon removal of volatile species, such as solvents and nitrate species, in the mesophase at relatively lower temperatures, and smaller pores form upon burning surfactant species. The presence of such a pore system would be beneficial to processes in which mass transfer takes place. The smaller pores coalesce into larger ones on further annealing the samples at higher temperatures. This 
is an important feature for applications, where larger pores are needed. Thermal annealing can expand the pores from 10 to 20 $\mathrm{nm}$ upon heating the films from 300 to $600{ }^{\circ} \mathrm{C}$. The MASA process is also applicable to forming mixed metal oxides. Here, we show mixed oxides of $\mathrm{Li}(\mathrm{I}), \mathrm{Mn}$ (III)/Mn(Iv), and $\mathrm{Co}(\mathrm{III}) / \mathrm{Co}(\mathrm{IV})$, where the pore size could be further reduced down to 5-6 nm with a much higher surface area. The method can be used to prepare many other mixed oxides, if their metal precursors are available to form the lyotropic liquid crystalline mesophase with non-ionic surfactants.

The meso- $\mathrm{LiMn}_{2-x} \mathrm{Co}_{x} \mathrm{O}_{4}$ (where $x$ is $0.5,1.0$, and 1.5) films display high electrochemical activities as water oxidation electrocatalysts with overpotentials as low as $0.280 \mathrm{~V}$ for $1 \mathrm{~mA} \mathrm{~cm}{ }^{-2}$. Although, still lower than some of the state-of-the art electrocatalysts such as layered double hydroxides and mixed-metal oxides, ${ }^{59-61}$ a remarkable enhancement in the electrocatalytic activity of the MMLs was obtained thanks to the MASA approach. The comparison between $\mathrm{LiCo}_{2} \mathrm{O}_{4}$ and $\mathrm{LiMn}_{2} \mathrm{O}_{4}$ clearly indicates that Co-sites are far more reactive than $\mathrm{Mn}$ sites. While the TOF values and thus, the activities of cobalt sites remain similar, the electrochemical performance of the $\mathrm{LiMn}_{2-x} \mathrm{Co}_{x} \mathrm{O}_{4}$ electrode increases with increasing the $x$ up to 0.5 and then stays the same in the 0.5-1 range. This trend implies that the decrease in the number of cobalt atoms is compensated with an increase in the surface area and, thus, the best electrocatalytic activity in terms of mass activity was obtained from the $\mathrm{LiMnCoO}_{4}$ electrode. The mass activity of the $\mathrm{LiMnCoO}_{4}$ electrode exhibits an exceptional value of $1743 \mathrm{~A}(\mathrm{~g}$ $\mathrm{Co}^{-1}$, which is superior to those of the previously reported MMLs (Table S1 $\dagger$ ). The films are stable and intact even under harsh catalytic conditions. They operate at current densities up to $120 \mathrm{~mA} \mathrm{~cm} \mathrm{~cm}^{-2}$ without losing their integrity and catalytic activity, where the overpotential increases linearly mainly due to the resistance of the FTO substrate (IR drop). This remarkable performance and stability clearly shows that the MASA approach can yield ideal electrocatalysts for water oxidation, and it should be explored further with different MMLs.

\section{Conflicts of interest}

There are no conflicts to declare.

\section{Acknowledgements}

We thank the Scientific and Technological Research Council of Turkey (TÜBITTAK) under project number $113 \mathrm{Z730}$ for the financial support. Ö. D. is a member of the Science Academy, Istanbul.

\section{Notes and references}

1 N. Linares, A. M. Silvestre-Albero, E. Serrano, J. SilvestreAlbero and J. G. Garcia-Martinez, Chem. Soc. Rev., 2014, 43, 7681.

2 M. S. Park, J. Kim, K. J. Kim, J. W. Lee, J. H. Kim and Y. Yamauchi, Phys. Chem. Chem. Phys., 2015, 17, 30963.
3 G. Wang, H. Liu, J. Horvat, B. Wang, S. Qiao, J. Park and H. Ahn, Chem.-Eur. J., 2010, 16, 11020.

4 N. Yang, F. Pang and J. Ge, J. Mater. Chem. A, 2015, 3, 1133. 5 J. Tang, J. Wang, L. K. Shrestha, Md. S. A. Hossain, Z. A. Alothman, Y. Yamauchi and K. Ariga, ACS Appl. Mater. Interfaces, 2017, 9, 18986.

6 I. Saptiama, Y. V. Kaneti, Y. Suzuki, Y. Suzuki, K. Tsuchiya, T. Sakae, K. Takai, N. Fukumitsu and Y. Yamauchi, Bull. Chem. Soc. Jpn., 2017, 90, 1174.

7 Y. Ren and P. G. Bruce, Chem. Soc. Rev., 2012, 41, 4909.

8 A. Walcarius, Chem. Soc. Rev., 2013, 42, 4098.

9 Y. V. J. Tang, R. R. Salunkhe, X. Jiang, A. Yu, K. C. -W. Wu and Y. Yamauchi, Adv. Mater., 2017, 29, 1604898.

10 A. H. Khan, S. Ghosh, B. Pradhan, A. Dalui, L. K. Shrestha, S. Archaryam and K. Ariga, Bull. Chem. Soc. Jpn., 2017, 90, 627.

11 G. Gardner, J. Al-Sharab, N. Danilovic, Y. B. Go, K. Ayers, M. Greenblatt and G. C. Dismukes, Energy Environ. Sci., 2016, 9, 184.

12 J. Wang, L. Li, H. Tian, Y. Zhang, X. Che and G. Li, ACS Appl. Mater. Interfaces, 2017, 9, 7100.

13 B. K. Lesel, J. S. Ko, B. Dunn and S. H. Tolbert, ACS Nano, 2016, 10, 7572.

14 W. Tang, Y. Zhu, Y. Hou, L. Liu, Y. Wu, K. P. Loh, H. Zhang and K. Zhu, Energy Environ. Sci., 2013, 6, 20093.

15 F. Jiao, K. M. Shaju and P. G. Bruce, Angew. Chem., Int. Ed., 2005, 44, 6550.

16 L. Luo, Y. Wang, H. Xiong and Y. Xia, Chem. Mater., 2007, 19, 4791.

17 F. Jiao, J. Bao, A. H. Hill and P. G. Bruce, Angew. Chem., Int. Ed., 2008, 47, 9711.

18 B. M. Hwang, S. J. Kim, Y. W. Lee, B. Han, S. B. Kim, W. S. Kim and K. W. Park, Int. J. Electrochem. Sci., 2013, 8, 9449.

19 S. Chen, Z. Chen and C. Cao, Electrochim. Acta, 2016, 199, 51.

20 H. Tüysüz, Y. Liu, C. Weidenthaler and F. Schüth, J. Am. Chem. Soc., 2008, 130, 14108.

21 F. Jiao, A. Harrison, J. C. Jumas, A. W. Chadwick, W. K. Kockelmann and P. G. Bruce, J. Am. Chem. Soc., 2006, 128, 5468.

22 L. Luo, Y. Wang, H. Xiong and Y. Xia, Chem. Mater., 2007, 19, 4791.

23 Y. Shi, S. Zhu, C. Zhu, Y. Li, Z. Chen and D. Zhang, Electrochim. Acta, 2015, 154, 17.

24 L. Han, P. Tang, A. Reyes-Carmona, B. Rodríguez-García, M. Torréns, J. R. Morante, J. Arbiol and J. R. GalanMascaros, J. Am. Chem. Soc., 2016, 138, 16037.

25 C. C. L. McCrory, S. Jung, J. C. Peters and T. F. Jaramillo, J. Am. Chem. Soc., 2013, 135, 16977.

26 X. Deng and H. Tüysüz, ACS Catal., 2014, 4, 3701.

27 M. Aksoy, S. V. K. Nune and F. Karadas, Inorg. Chem., 2016, 55, 4301.

28 P. Yang, D. Zhao, D. I. Margolese, F. Bradley, B. F. Chemalka and G. D. Stucky, Nature, 1998, 396, 152.

29 D. Grosso, G. J. A. A. Soler-Illia, E. L. Crepaldi, B. Charleux and C. Sanchez, Adv. Funct. Mater., 2003, 13, 37. 
30 D. Grosso, C. Boissière, B. Smarsly, T. Brezesinski, N. Pinna, P. A. Albouy, H. Amenitsch, M. Antonietti and C. Sanchez, Nat. Mater., 2004, 3, 787.

31 N. D. Petkovich, A. Stein and R. A. Caruso, Chem. Soc. Rev., 2013, 42, 3721.

32 C. Karakaya, Y. Türker, C. Albayrak and Ö. Dag, Chem. Mater., 2011, 23, 3062.

33 C. Karakaya, Y. Türker and Ö. Dag, Adv. Funct. Mater., 2013, 23, 4002.

34 C. Avci, A. Aydin, Z. Tuna, Y. Yavuz, Y. Yamauchi, N. Suzuki and Ö. Dag, Chem. Mater., 2014, 26, 6050.

35 F. M. Balcı, O. U. Kudu, E. Yilmaz and Ö. Dag, Chem.-Eur. J., 2016, 22, 18873.

36 C. J. Brinker, Y. Lu, A. Sellinger and H. Fan, Adv. Mater., 1999, 11, 579.

37 D. Grosso, F. Cagnol, C. J. A. A. Soler-Illia, E. L. Crepaldi, H. Amenitsch, A. Brunet-Bruneau, A. Bourgeois and C. Sanchez, Adv. Funct. Mater., 2004, 14, 309.

38 X. Chen, M. Knez, A. Berger, K. Nielsch, U. Gösele and M. Steinhart, Angew. Chem., Int. Ed., 2007, 46, 6829.

39 Ö. Çelik and Ö. Dag, Angew. Chem., Int. Ed., 2001, 40, 3800.

40 C. Albayrak, A. M. Soylu and Ö. Dag, Langmuir, 2008, 24, 10592.

41 C. Albayrak, A. Cihaner and Ö. Dag, Chem.-Eur. J., 2012, 18, 4190.

42 G. Saat, F. M. Balci, E. P. Alsac, F. Karadas and Ö. Dag, Small, 2018, 1701913, 1.

43 C. W. Cady, G. Gardner, Z. O. Mron, M. Retuerto, Y. B. Go, S. Segan, M. Greenblatt and G. C. Dismukes, ACS Catal., 2015, 5, 3403.

44 G. Maino, J. D'Haen, F. Mattelaer, C. Detavernier, A. Hardy and M. K. Van Bael, J. Mater. Chem. A, 2016, 4, 18457.

45 W. Huang and R. Frech, Solid State Ionics, 1996, 86-88, 395.
46 H. Porthault, R. B. Hadjean, F. Le Cras, C. Bourbon and S. Franger, Vib. Spectrosc., 2012, 62, 152.

47 R. B. Hadjean and J. P. Pereira-Ramos, Chem. Rev., 2010, 110, 1278.

48 D. A. Fine, J. Am. Chem. Soc., 1962, 84, 1139.

49 C. Albayrak, A. M. Soylu and Ö. Dag, J. Colloid Interface Sci., 2010, 341, 109.

50 S. J. Hwang, D. H. Park, J. H. Choy and G. Campet, J. Phys. Chem. B, 2004, 108, 12713.

51 A. Paolone, A. Sacchetti, T. Corridoni, P. Postorino, R. Cantelli, G. Rousse and C. Masquelier, Solid State Ionics, 2004, 170, 133.

52 J. C. Knight, S. Therese and A. Manthiram, J. Electrochem. Soc., 2015, 162, A426.

53 C. Lai, J. Chen, J. C. Knight, A. Manthiram and A. Navrotsky, ChemPhysChem, 2016, 17, 1973.

54 A. J. Esswein, M. J. McMurdo, P. N. Ross, A. T. Bell and T. D. Tilley, J. Phys. Chem. C, 2009, 113, 15068.

55 C. Costentin, S. Drouet, M. Robert and J.-M. Savéant, J. Am. Chem. Soc., 2012, 134, 11235.

56 S. Pintado, S. Goberna-Ferron, E. C. Escudero-Adan and J. R. Galan-Mascaros, J. Am. Chem. Soc., 2013, 135, 13270.

57 S. V. K. Nune, A. T. Basaran, E. Ülker, R. Mishra and F. Karadas, ChemCatChem, 2017, 9, 300.

58 E. P. Alsaç, E. Ülker, S. V. K. Nune, Y. Dede and F. Karadas, Chem.-Eur. J., 2018, 24, 4856.

59 L. Trotochaud, J. K. Ranney, K. N. Williams and S. W. Boettcher, J. Am. Chem. Soc., 2012, 134, 17253.

60 P. F. Liu, S. Yang, B. Zhang and H. G. Yang, ACS Appl. Mater. Interfaces, 2016, 8, 34474.

61 Y. Wang, Y. Zhang, Z. Liu, C. Xie, S. Feng, D. Liu, M. Shao and S. Wang, Angew. Chem., Int. Ed., 2017, 129, 5961. 